\title{
Crescimento de dois genótipos de maracujazeiro-amarelo sob condições de salinidade ${ }^{1}$
}

\author{
Jeferson Dutra Bezerra* ${ }^{2 *}$ Walter Esfrain Pereira ${ }^{2}$,José Madson da Silva², Roberto Wagner Cavalcanti Raposo ${ }^{2}$
}

$10.1590 / 0034-737 X 201663040010$

\begin{abstract}
RESUMO
A elevada salinidade do solo, na maioria dos mananciais de diferentes áreas da região nordeste, a qual é considerada a mais expressiva na produção do maracujazeiro-amarelo, tem afetado a formação de mudas e o estabelecimento da cultura sob manejo convencional. Objetivou-se, com este experimento, comparar dois genótipos de maracujazeiroamarelo, submetidos a diferentes condutividades elétricas (CE) da água de irrigação, em ambiente protegido, por meio de variáveis de crescimento. O experimento foi conduzido em blocos ao acaso, com quatro repetições, no esquema fatorial $5 \times 2$, sendo cinco valores de condutividade elétrica da água de irrigação: 0,$3 ; 2,0 ; 4,0 ; 6,0$ e $8,0 \mathrm{dS} \mathrm{m}^{-1}$, e dois genótipos de maracujazeiro-amarelo: 'BRS Sol do Cerrado'e 'Redondo Amarelo'. O 'BRS Sol do Cerrado' sobressai-se em relação à taxa relativa de crescimento quando comparado com a do 'Redondo Amarelo', cuja taxa reduz com o aumento da salinidade da água. De modo geral, a alta salinidade da água de irrigação promove redução do crescimento dos genótipos estudados.
\end{abstract}

Palavras-chave: Passiflora edulis; matéria; estresse salino.

\section{ABSTRACT}

\section{Growth of two genotypes of yellow passion fruit under saline conditions}

The high salinity in the soil in most watersheds in different areas of the Northeast, considered as the most significant in the production of yellow passion fruit, has affected the formation of seedlings and crop establishment under conventional management. The objective of this experiment was to compare two genotypes of yellow passion fruit under different electrical conductivities (EC) of the irrigation water in a protected environment through growth variables. The experiment was conducted in a randomized block design with four replications in a $5 \times 2$ factorial design with five values of electrical conductivity of irrigation water: $0.3,2.0,4.0,6.0$ and $8.0 \mathrm{dS} \mathrm{m}^{-1}$, using two genotypes of yellow passion: BRS Sol do Cerrado and Redondo Amarelo. The BRS Sol do Cerrado excels with respect to relative growth rate compared to the Redondo Amarelo, whose rate reduces with increasing salinity. In general, the high salinity of the irrigation water causes a reduction in the growth of the genotypes studied.

Key words: Passiflora edulis; biomass; salinity stress.

\footnotetext{
Submetido em 26/02/2015 e aprovado em 08/03/2016.

Este trabalho é parte da dissertação de mestrado do primeiro autor.

${ }^{2}$ Universidade Federal da Paraíba, Areia, Paraíba, Brasil. jefersondutra_sbpb@hotmail.com; walter.ufpb@yahoo.com.br; josemadsonp@hotmail.com; rwcraposo@hotmail.com *Autor correspondente: jefersondutra_sbpb@hotmail.com
} 


\section{INTRODUÇÃO}

O maracujazeiro está entre as frutíferas de maior expressão econômica, no Brasil, apresentando maior destaque nas últimas décadas (Rodolfo Júnior et al., 2008; Dias et al., 2011). Esta expressividade, além de estar associada às condições edafoclimáticas favoráveis para o seu crescimento, desenvolvimento e produção (Mendonca et al., 2006), está também direcionada às características físicoquímicas dos frutos e à grande aceitação do suco e da fruta "in natura" no mercado nacional (Faleiro et al., 2008).

Na região nordeste, a área colhida, a quantidade produzida e o rendimento médio são de 44.932 ha, 563.346 t de frutos e 12,538 $\mathrm{t} \mathrm{ha}^{-1}$, respectivamente, sendo que, a região responde por 72,6\% da produção nacional de maracujá-amarelo (IBGE, 2012). Mesmo a região nordeste sendo considerada como a mais expressiva produtora do maracujazeiro- amarelo, a elevada salinidade dos solos e dos mananciais, em diversas áreas da região, tem comprometido a formação de mudas e o estabelecimento da cultura sob manejo convencional. Além disso, a qualidade da água de irrigação, nas principais áreas de cultivo de maracujá, nos estados da Paraíba e do Rio Grande do Norte, é, na maioria, oriundo de mananciais superficiais e subterrâneos que apresentam condutividades elétricas superiores a $1,5 \mathrm{dS} \mathrm{m}^{-1}$ (Cavalcante et al., 2009). Ressalte-se, ainda, que a salinidade, em muitas regiões de áreas áridas e semiáridas, constitui sério obstáculo ao sistema de produção, tanto pelas alterações dos atributos físicos e químicos dos solos como pela ação dos íons especíûcos sobre a germinação, o crescimento, a produção e a nutrição de plantas (Cavalcante et al., 2010). Nesse mesmo sentido, Ahmed \& Montani (2010) relatam que os efeitos mais marcantes da salinidade sobre as plantas refletem em alterações do potencial osmótico, da toxicidade iônica e do desequilíbrio da absorção dos nutrientes, reduzindo assim o seu crescimento, com sérios prejuízos à atividade agrícola.

Sabe-se que a análise de crescimento é uma das formas de se estudar o estado morfisiológico das plantas quando submetidas aos mais diferentes tipos de estresse, tanto bióticos como abióticos. Por essa razão, a análise de crescimento apresenta-se como uma técnica válida para se avaliarem as bases fisiológicas da produção e para se enfatizar a influência exercida pelas variáveis ambientais, genéticas e agronômicas. Ela se baseia no fato de que, aproximadamente, $90 \%$ da matéria seca produzida pelas plantas é proveniente das atividades fotossintéticas e, o restante, acumula-se em função da absorção de água e de nutrientes (Benincasa, 2003; Floss, 2004). Por essa razão, objetivou-se, com este experimento, avaliar o crescimento de dois genótipos de maracujazeiro-amarelo, sob condições de salinidade.

\section{MATERIAL E MÉTODOS}

O experimento foi conduzido entre maio e agosto de 2012, em casa de vegetação, no Centro de Ciências Agrárias da Universidade Federal da Paraíba, no município de Areia, PB, Brasil (6 $6^{\circ} 57^{\prime} 42^{\prime \prime}$ S, 3541'43" O, 573 m). As temperaturas médias e a umidade relativa do ar no período de execução do experimento estão representadas na Figura 1. O experimento foi conduzido sob delineamento em blo$\cos$ ao acaso, com quatro repetições, no esquema fatorial $5 \times 2$, correspondendo a cinco valores da condutividade elétrica da água de irrigação $\left(0,3 ; 2,0 ; 4,0 ; 6,0\right.$ e $\left.8,0 \mathrm{dS} \mathrm{m}^{-1}\right)$ e a dois genótipos de maracujazeiro-amarelo. As sementes do maracujazeiro foram adquiridas na EMBRAPACERRADOS (CPAC) e no comércio local, sendo, as sementes, de um genótipo híbrido ('BRS Sol do Cerrado') e de outro, não híbrido ('Redondo Amarelo').

Cada parcela experimental foi composta por cinco mudas de cada genótipo. Na formação das mudas foram utilizados tubetes com $700 \mathrm{~mL}$ de substrato composto de solo e esterco bovino, na proporção de 9:1, conforme utilizado por Cavalcante et al. (2011). O substrato apresentou: condutividade elétrica de $4,15 \mathrm{dS} \mathrm{m}^{-1}$, percentagem de sódio trocável 2,28\%, com análise granulométrica indicando $490 \mathrm{~g} \mathrm{~kg}^{-1}$ de areia, $178,8 \mathrm{~g} \mathrm{~kg}^{-1}$ de silte e 331,2 $\mathrm{g} \mathrm{kg}^{-1}$ de argila, com densidade do solo de $1,08 \mathrm{~g} \mathrm{~cm}^{-3}$, densidade de partícula de $2,69 \mathrm{~g} \mathrm{~cm}^{-3}$ e porosidade total de 59,8\%. Após os recipientes terem sido preenchidos com substrato, foram irrigados até atingir a capacidade de campo e, em seguida, em cada recipiente foram depositadas duas sementes. Decorridos 22 dias após semeadura (DAS) e germinação das sementes, procedeu-se ao desbaste das plântulas, deixando-se a mais vigorosa. No período correspondente à germinação e ao crescimento inicial das plântulas, as irrigações foram feitas de modo igual, em todas elas, aplicando-se água não salina $\left(0,3 \mathrm{dS} \mathrm{m}^{-1}\right)$ uma vez ao dia, utilizando-se regador, de forma a manter a umidade do solo próxima à capacidade de campo.

Após 30 dias da semeadura e estabilização da emergência das plântulas, iniciou-se a aplicação dos tratamentos e da irrigação, com manejo hídrico diferenciado, conforme a demanda hídrica, aplicando-se um volume único às plantas em todos os tratamentos, em função da evapotranspiração média, obtida por pesagem, de forma a serem mantidos próximos à capacidade de campo. Para tanto, diariamente e no mesmo horário, os tubetes com as respectivas plantas foram pesados, para verificação da quantidade de água evapotranspirada e, posteriormente, adicionados os volumes necessários para manter a capacidade hídrica necessária às plantas, utilizando-se um Becker. Os tratamentos com as águas salinizadas foram aplicados durante um período de 76 dias. 
As águas de irrigação foram preparadas pela adição, à água de abastecimento, de cloreto de sódio $(\mathrm{NaCl})$ puro (PA), de maneira a se obter o valor desejado da condutividade elétrica, aferida por condutivímetro CD-860. As águas salinas foram armazenadas em baldes plásticos, identificados conforme cada nível salino, sendo realizadas, periodicamente, medições da salinidade das águas armazenadas para corrigir possíveis alterações.

Para a avaliação do crescimento das plantas, foram realizadas medições periódicas semanais, a partir dos 50 dias após a semeadura (DAS), e finalizadas aos 106 dias após a semeadura, totalizando 56 dias de avaliação. A altura de mudas (AM) foi avaliada semanalmente, com régua graduada em cm, tomando-se como referência a distância do colo da planta até a inserção da última folha formada. A partir dos dados de altura, foi calculada a taxa relativa de crescimento em altura (TRC-A), em $\mathrm{mm} \mathrm{m}^{-1} \mathrm{dia}^{-1}$, por meio da seguinte equação (Benincasa, 2003; Floss, 2004):

$$
\mathrm{TRC}=\frac{\ln M 2-\ln M 1}{t 2-t 1}
$$

$T R C=(1)$, em que: M2: medição final da altura; M1: medição inicial da altura; t2-t1: Intervalo de tempo; ln: Logaritmo neperiano.

Em seguida, realizou-se a separação das raízes, folhas e caules, os quais foram acondicionados em sacos de papel, depois colocados em estufa, a $65^{\circ} \mathrm{C}$, durante 72 horas, para secagem até massa constante, obtendo-se as matérias secas da raiz (FSR), do caule (FSC) e das folhas (FSF), cujo somatório resultou na matéria seca total (FST). A área foliar (AF) foi quantificada a partir de imagens fotográficas das folhas, digitalizadas em scanner HP F2050 e processadas no software Sigma Scan Pro 5.0 Demo (www.spss.com). A área foliar específica (AFE) foi quantificada pela divisão entre a área foliar (AF) e a massa da matéria seca foliar (MMSF), conforme a equação 2, (Floss, 2004):

$$
A F E=\frac{A F}{M M S E}
$$

$\mathrm{AF}=$ área foliar $\left(\mathrm{cm}^{2}\right) ; \mathrm{MMSF}=$ massa da matéria seca foliar $(\mathrm{g})$.

Os dados foram submetidos à análise de variância $\mathrm{e}$ os efeitos dos cultivares foram avaliados pelo teste F. Para avaliar o efeito da condutividade elétrica, realizou-se análise de regressão polinomial. Todas as análises estatísticas foram realizadas no programa SAS 9.3 (Sas Institute Inc, 2011).

\section{RESULTADOS E DISCUSSÃO}

As variáveis morfofisiológicas dos genótipos de maracujazeiro-amarelo, sob condições de salinidade: altura de mudas, taxa relativa de crescimento, massa de matéria seca da raiz, não diferenciaram de forma significativa para o fator genótipo; por outro lado, para o fator condutividade elétrica da água, altura de mudas, massa de matéria seca da folha, massa de matéria seca da raiz, massa de matéria seca total e área foliar específica foram influenciados a $1 \%$ de probabilidade de erro (Tabela 1 ).

Constata-se que não houve interação entre genótipo e condutividade sobre a altura de muda (AM). Ajustando-se ao modelo linear decrescente, em função do aumento da condutividade elétrica da água de irrigação, observa-se decréscimo com o aumento da condutividade elétrica da água de irrigação. Para os cultivares "Brs Sol do Cerrado" (Figura 2A) e o "Redondo Amarelo" (Figura 2B), foram evidenciados valores máximos de 15,15 e 15,03 $\mathrm{cm}$, quando irrigados com a menor condutividade elétrica da água, e redução do crescimento em 24,7 e $24,5 \%$, respectivamente, quando irrigados com água de maior condutividade elétrica. Segundo Munns (2011), se quantidades excessivas de $\mathrm{Na}^{+}$ou $\mathrm{Cl}^{-}$são absorvidas pela planta, podem-se atingir níveis tóxicos nas folhas mais velhas com a transpiração, o que, aliado a uma área foliar menor,

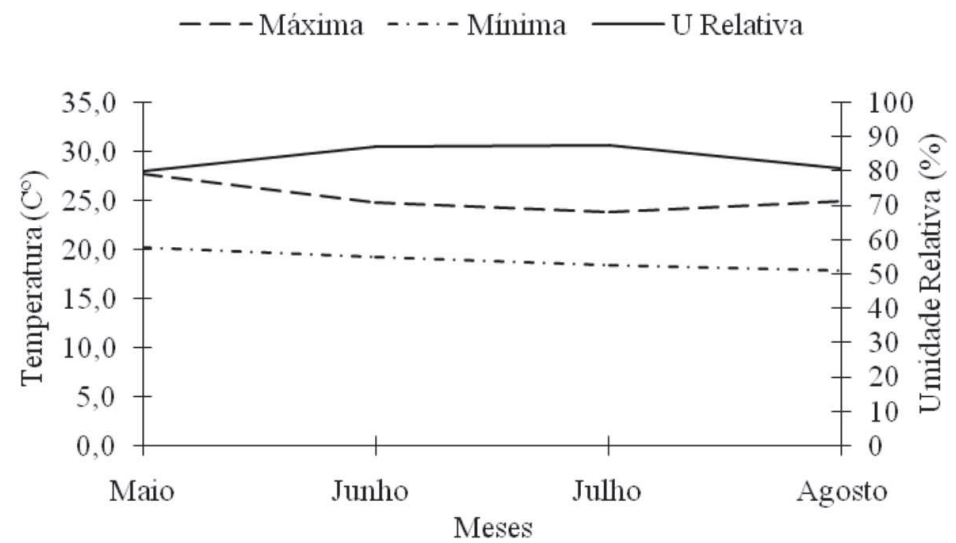

Figura 1: - Representação gráfica das médias mensais de temperatura e de umidade relativa do ar no interior do viveiro da casa de vegetação.

Rev. Ceres, Viçosa, v. 63, n.4, p. 502-508, jul/ago, 2016 
poderá limitar o fluxo de compostos de carbono para os meristemas e zonas de crescimento nas folhas. Mesquita et al. (2012), avaliando a produção de mudas de maracujazeiro-amarelo submetidas à salinidade, também constataram que o aumento da condutividade elétrica da água de irrigação reduziu o crescimento durante a formação das mudas de maracujazeiro-amarelo.

Em relação à taxa relativa de crescimento em altura (TCRA), evidenciou-se que o ‘BRS Sol do Cerrado’ não sofreu influência da salinidade e não se ajustou a nenhum modelo

Tabela 1: Resumo da análise de variância dos caracteres: Altura de mudas (AM), Taxa relativa de crescimento da altura (TRCA), Massa de matéria seca foliar (MMSF), Massa de matéria seca da raiz (MMSR), Massa de matéria seca total (MMST) e Área foliar específica (AFE) dos genótipos de maracujazeiro-amarelo ‘BRS Sol do Cerrado’ e 'Redondo Amarelo', em função da condutividade elétrica da água de irrigação

\begin{tabular}{lcccc}
\hline \multicolumn{5}{c}{ Quadrado Médio } \\
\hline FV & GL & AM & TRCA & MMSF \\
\hline GEN & 1 & $0,0547^{\text {ns }}$ & $0,00000150^{\text {ns }}$ & $0,090730^{* *}$ \\
CEA & 4 & $19,8890^{* *}$ & $0,00001281^{\text {ns }}$ & $0,511617^{* *}$ \\
GENXCEA & $(4)$ & $1,8421^{\text {ns }}$ & $0,00001375^{\text {ns }}$ & $0,047010^{\text {ns }}$ \\
ERRO & 27 & 4,6021 & 0,00000641 & 0,023698 \\
\hline CV(\%) & 16,2 & 55,02 & 14,75 \\
\hline FV & Quadrado Médio & & AFE \\
\hline GEN & GL & MMSR & MMST & $0,000001^{* *}$ \\
CEA & 1 & $0,000665^{\text {ns }}$ & $0,637613^{* *}$ & $0,000004^{* *}$ \\
GENXCEA & 4 & $0,054816^{* *}$ & $1,486598^{* *}$ & $0,2733492^{\text {ns }}$ \\
ERRO & $(4)$ & $0,007204^{\text {ns }}$ & $0,152116^{\text {ns }}$ & 0,09213820 \\
\hline CV(\%) & 27 & 0,008985 & 0,085205 & 8,94 \\
\hline
\end{tabular}

ns $=$ não significativo ${ }^{*}=$ significativo a $5 \%$ de probabilidade e ${ }^{* *}=$ significativo a $1 \%$ de probabilidade pelo teste ' $\mathrm{F}$ '

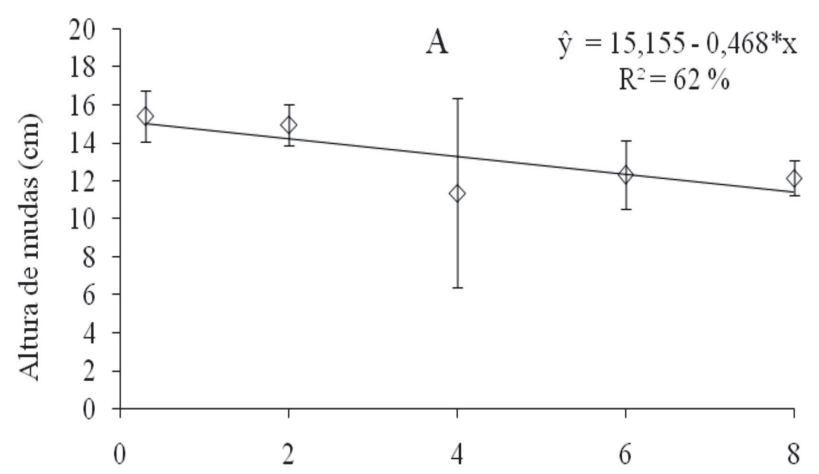

Condutividade elétrica da água $\left(\mathrm{dS} \mathrm{m}^{-1}\right)$

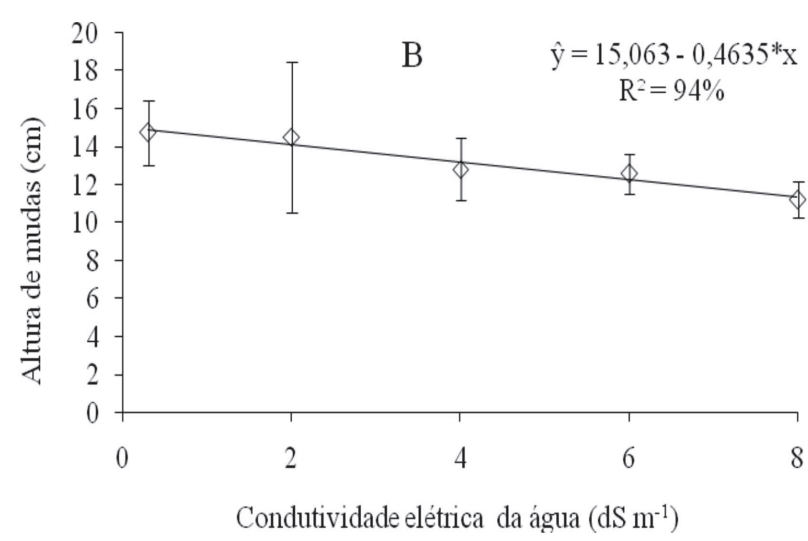

Figura 2: Altura de mudas (AM) dos genótipos de maracujazeiroamarelo 'BRS Sol do Cerrado' (A), 'Redondo Amarelo'(B), em função da condutividade elétrica da água de irrigação.
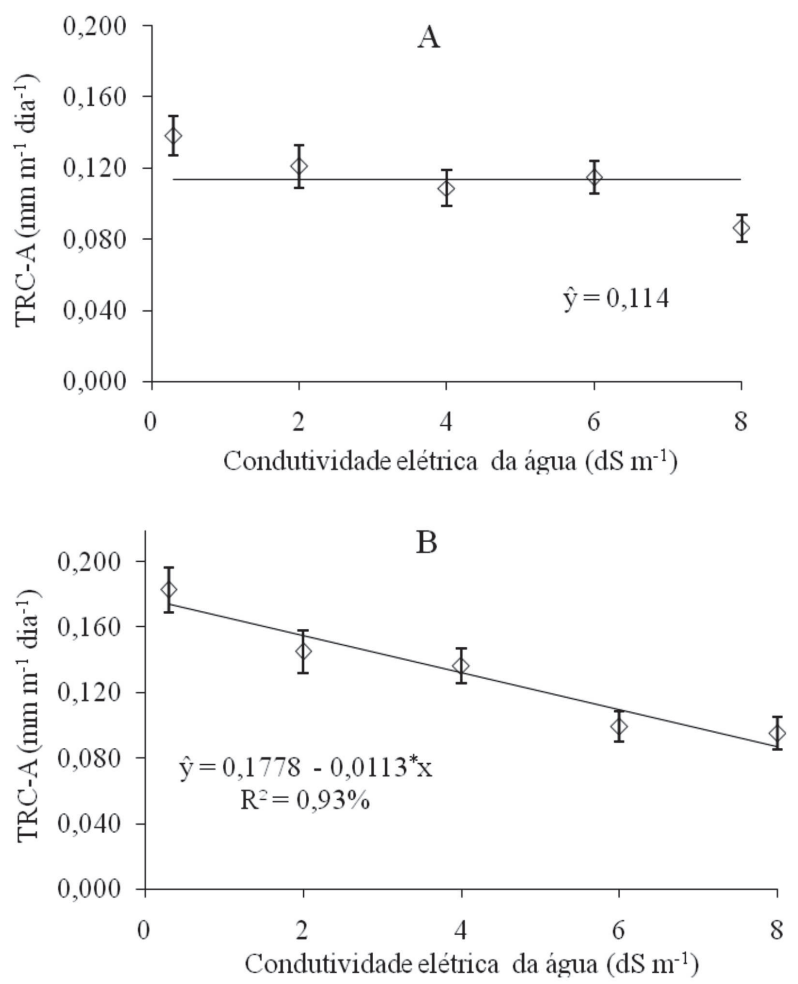

ns: não significativo; * significativo a $5 \%$ pelo teste ' $F$ '

Figura 3: Taxa relativa de crescimento em altura de mudas dos genótipos de maracujazeiro-amarelo 'BRS Sol do Cerrado' (A) e 'Redondo Amarelo' (B), em função da condutividade elétrica da água de irrigação. 
de regressão, com valor médio de $0,114 \mathrm{~mm} \mathrm{~m}^{-1} \mathrm{dia}^{-1}$ (Figura 3A). Já, para o 'Redondo Amarelo', houve efeito significativo das condutividades elétricas da água de irrigação sobre TRC-A, ajustando-se ao modelo de regressão linear (Figura 3B), verificando-se que o aumento da condutividade elétrica da água de irrigação diminuiu a TRC-A de 0,177 para $0,87 \mathrm{~mm} \mathrm{~m}^{-1} \mathrm{dia}^{-1}$, correspondendo a $51,05 \%$ de decréscimo. Aguiar Netto et al. (2000) afirmam que o crescimento relativo é um índice indicado para estudar o efeito de práticas agronômicas, pois reflete a eficiência do uso das reservas do vegetal, uma vez que representa a capacidade da planta de produzir material novo, em função do material já existente. Neste sentido, isso pode ser um indicativo de que o genótipo 'BRS Sol do Cerrado' utilizou mais eficientemente suas reservas para promover melhoria de crescimento em altura das mudas. Verificou-se influência da salinidade elevada sobre a MMSF, MMSR e MMST, ajustando-se ao modelo linear decrescente. Foram observados decréscimos de 50,4 e 41,2\% da MMSF (Figura 4A e 4B), de 30,6 e 20,5\% da MMSR (Figura 5A e 5B), e de 42,1 e 32,8\% da MST (Figura 6A e 6B) na condutividade elétrica da água de $8\left(\mathrm{dS} \mathrm{m}^{-1}\right)$, para 'BRS Sol do Cerrado' e 'Redondo Amarelo', respectivamente. No mesmo sentido, Costa et al. (2005) e Cruz et al. (2006), também estudando o efeito da salinidade no maracujazeiro-amarelo, observaram redução de até $78,17 \%$ para a massa de matéria seca da folha e de $20 \%$ para

A

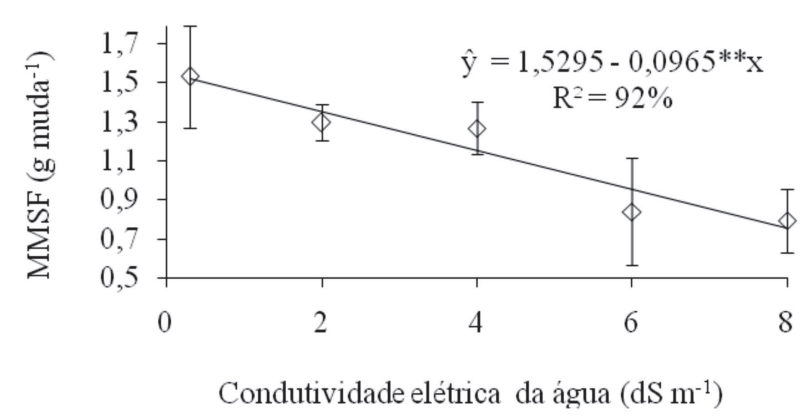

B

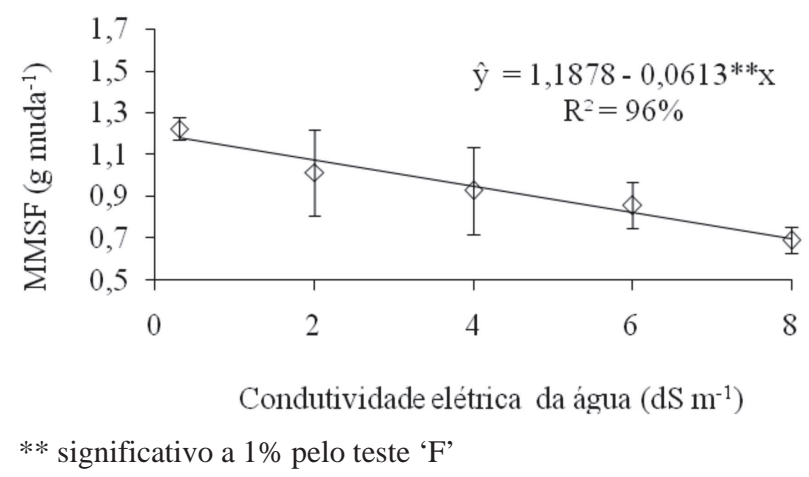

Figura 4: Massa de matéria seca da folha dos genótipos de maracujazeiro-amarelo 'BRS Sol do Cerrado'(A) e 'Redondo Amarelo'(B), em função da condutividade elétrica da água de irrigação.

Rev. Ceres, Viçosa, v. 63, n.4, p. 502-508, jul/ago, 2016 a massa de matéria seca da raiz, com a aplicação de água salina de até $6,5 \mathrm{dS} \mathrm{m}{ }^{-1}$. Já Costa et al. (2012) verificaram redução da massa de matéria seca total de melancieiras,

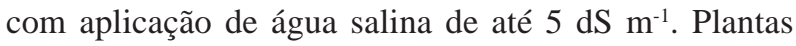
cultivadas em ambientes salinos sofrem inibição do crescimento. Isso pode ser atribuído ao déficit hídrico causado por grandes quantidades de sais solúveis na zona radicular, o qual promove uma redução da turgescência, resultando na diminuição da expansão celular, reduzindo a taxa de crescimento das plantas (Bai et al., 2008; Khalid \& Silva, 2010).

Para a área foliar específica (AFE), verificou-se ajuste ao modelo linear crescente. Constatou-se que 'BRS Sol do Cerrado' teve máximo valor de $386,3 \mathrm{~cm}^{2} \mathrm{~g}^{-1}$, com aumento de $46,1 \%$, na maior condutividade elétrica da água de irrigação de $8\left(\mathrm{dS} \mathrm{m}^{-1}\right)$ (Figura 7A). Já 'Redondo Amarelo' expressou máximo valor de $398,5 \mathrm{~cm}^{2} \mathrm{~g}^{-1}$ com aumento de $37,7 \%$, quando também se aumentou a condutividade elétrica da água de irrigação (Figura 7B). AAFE é um indicador de espessura foliar. Segundo Taiz e Zaiger (2009), a salinidade está associada ao estresse hídrico, assim, na medida em que decresce o conteúdo de água da planta, suas células contraem-se e diminui a pressão de turgor contra as paredes celulares, tornando a membrana plasmática mais espessa e comprimida, porque ela cobre uma área menor que a anterior.

A

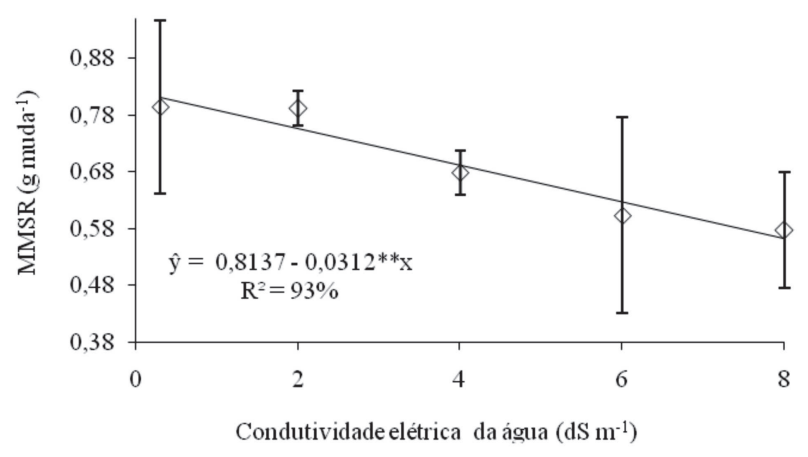

$\mathrm{B}$

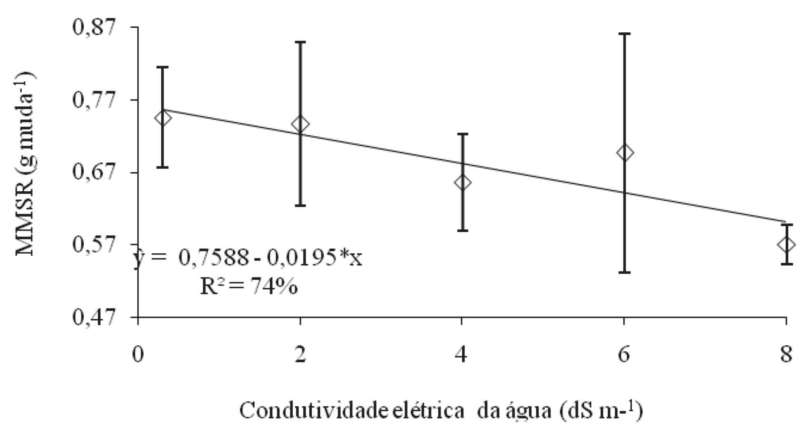

** significativo a $1 \%$ pelo teste ' $\mathrm{F}$ '

Figura 5: Massa de matéria seca da raiz dos genótipos de maracujazeiro-amarelo 'BRS Sol do cerrado'e 'Redondo Amarelo', em função da condutividade elétrica da água de irrigação. 
A

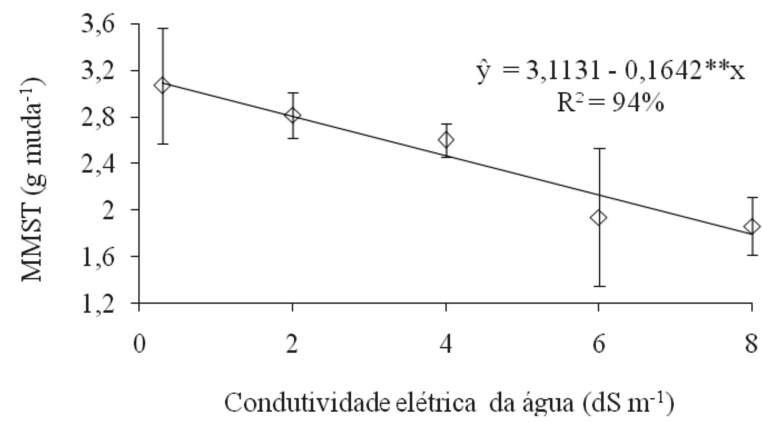

B

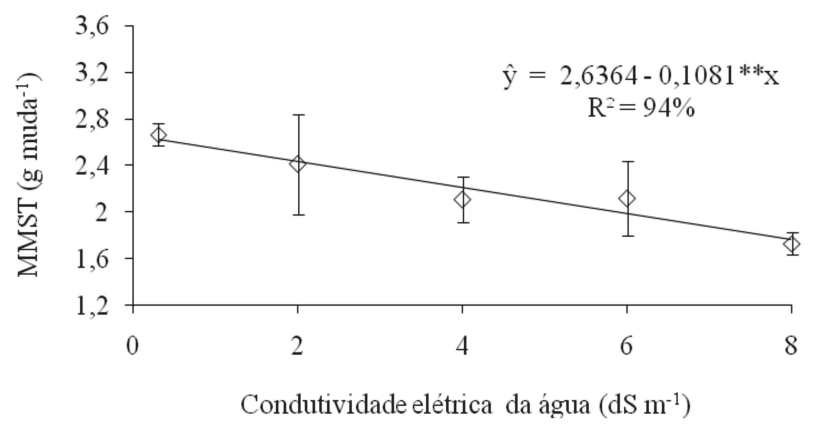

** significativo a $1 \%$ pelo teste ' $\mathrm{F}$ '

Figura 6: Massa de matéria seca total dos genótipos de maracujazeiro-amarelo 'BRS Sol do Cerrado'(A) e 'Redondo Amarelo'(B), em função da condutividade elétrica da água de irrigação.

\section{CONCLUSÕES}

A altura de mudas e os parâmetros de matéria seca são afetados pela salinidade da água para os genótipos estudados.

O cultivar 'BRS Sol do Cerrado' sobressai-se com relação à taxa relativa de crescimento, quando se compara com a do cultivar 'Redondo Amarelo', cuja taxa reduz com o aumento da salinidade da água.

De um modo geral, a alta salinidade da água de irrigação promove redução do crescimento dos genótipos estudados.

\section{REFERÊNCIAS}

Aguiar Netto AO, Rodrigues JD \& Pinho SL (2000) Análise de crescimento na cultura da batata, submetidas a diferentes laminas de irrigação. Pesquisa Agropecuária Brasileira, 35:901-907.

Ahmed BA \& Montani IS (2010) Effect of saline water irrigation and manure application on the available water. Agricultural Water Management, 97:165-170.

Bai W \& Teixeira da Silva JA (2008) Some physiological responses of chinese iris to salt stress. Pedosphere, 18:454-463.

Benincasa MMP (2003) Análise de crescimento de plantas. Jaboticabal, FUNEP. 41p.

Cavalcante LF, Dias TJ, Nascimento R \& Freire JLO (2011) Clorofila e carotenóides em maracujazeiro-amarelo irrigado com águas salinas no solo com biofertilizante bovino. Revista Brasileira Fruticultura, Volume Especial: 699-705.
$\mathrm{B}$

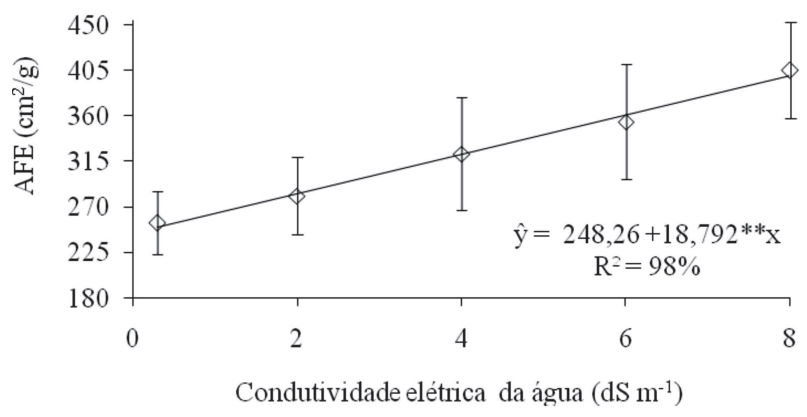

A

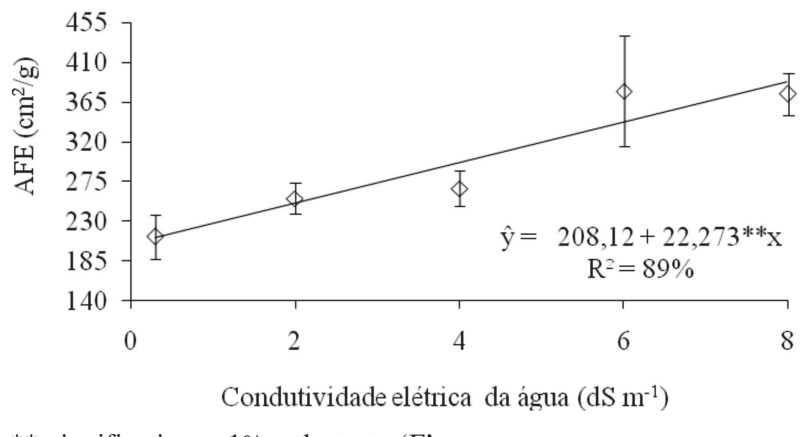

** significativo a $1 \%$ pelo teste ' $\mathrm{F}$ '

Figura 7: Área foliar específica dos genótipos de maracujazeiro-amarelo 'BRS Sol do Cerrado'(A) e 'Redondo Amarelo'(B), em função da condutividade elétrica da água de irrigação.

Cavalcante LF, Silva GF, Gheyi HR, Dias TJ, Alves JC \& Costa APM (2009) Crescimento de mudas de maracujazeiro amarelo em solo salino com esterco bovino líquido fermentado. Revista Brasileira de Ciências Agrárias, 4:414-420.

Cavalcante LF, Vieira MS, Santos AF, Oliveira WM \& Nascimento JAM (2010) Água salina e esterco bovino líquido na formação de mudas de goiabeira cultivar Paluma. Revista Brasileira de Fruticultura, 32:251-261.

Costa EG, Carneiro PT, Soares FAL, Fernandes PD, Gheyi HR \& Cavalcante LF (2005) Crescimento inicial do maracujazeiro amarelo sob diferentes tipos e níveis de salinidade da água de irrigação. Revista Brasileira de Engenharia Agrícola e Ambiental, 9:242-247.

Costa FGB, Fernandes MB, Barreto HBF, Oliveira AFM \& Santos WO (2012) Crescimento da melancia e monitoramento da salinidade do solo com TDR sob irrigação com águas de diferentes salinidades. Irriga, 17:327-336.

Cruz JL, Pelacani CR, Coelho EF, Caldas RC, Almeida AQ \& Queiroz JR (2006) Influência da salinidade sobre o crescimento, absorção e distribuição de sódio, cloro e macronutrientes em plântulas de maracujazeiro-amarelo. Bragantia, 65:275-284.

Dias TJ, Cavalcante LF, Freire JLO, Nascimento JAM, Cavalcante MZB \& Santos GP (2011) Qualidade química de frutos do maracujazeiro-amarelo em solo com biofertilizante irrigado com águas salinas. Revista Brasileira de Engenharia Agrícola e Ambiental, 15:229-236.

Faleiro FG, Junqueira NTV \& Braga MF (2008) Pesquisa e desenvolvimento do maracujá. In: Albuquerque ACS \& Silva RC (Eds.) Agricultura Tropical: Quatro Décadas de Inovações Tecnológicas, Institucionais e Políticas. Brasília, Embrapa. p.411-416.

Rev. Ceres, Viçosa, v. 63, n.4, p. 502-508, jul/ago, 2016 
Floss EL (2004) Fisiologia das plantas cultivadas. Passo Fundo, Editora da UPF.536p.

IBGE - Instituto Brasileiro de Geografia e Estatística (2012) Sistema IBGE de recuperação automática SIDRA. Disponível em: <http://www.sidra.ibge.gov.br/bda/tabela/protabl.asp?c=1613\&z $=\mathrm{p} \& \mathrm{o}=35 \& \mathrm{i}=\mathrm{P}>$ Acessado em: 02 de junho de 2014 .

Khalid A \& Silva JAT (2010) Yield, essential oil and pigment content of Calendula officinalis L. flower heads cultivated under salt stress conditions. Scientia Horticulturae, 126:297-305.

Mendonca V, Neto SEA, Ramos JD, Carvalho JG \& Junior VCA (2006) Fontes e doses de fósforo para o maracujazeiro-amarelo. Revista Caatinga, 19:65-70.

Mesquita FO, Cavalcante LF, Pereira WE, Rebequi AM, Neto AJL \& Nunes JC (2012) Produção de mudas de maracujazeiro amarelo submetidas à salinidade em solo com biofertilizante bovino. Ciencia del Suelo, 30:31-41.
Munns R (2011) Plant adaptations to salt and water stress: differences and commonalities. Advances in Botanical Research, 57:1-32

Rodolfo Júnior F, Cavalcante LF \& Buriti ES (2008) Crescimento e produção do maracujazeiro-amarelo em solo com biofertilizante e adubação mineral com NPK. Revista Caatinga, 21:134-145.

SAS Institute Inc. (2011) Statistical Analysis System user's guide. Version 9.3. Cary, Statistical Analysis System Institute. 513p.

Taiz L \& Zeiger E (2009) Fisiologia Vegetal. Porto Alegre, Artmed. 848p. 